\title{
Acute promyelocytic leukemia: from genetic lesions identification to molecularly targeted therapy
}

\author{
Marcelina Majka, Paweł R. Bednarek, Matylda Nowicki, Jagoda Chełmikowska, \\ Krystian Kaczmarek, Eliza Kędzierska, Krzysztof Lewandowski®i \\ Department of Hematology and Bone Marrow Transplantation, Medical Faculty, Poznan University \\ of Medical Sciences, Poznan, Poland
}

\begin{abstract}
Acute promyelocytic leukemia (APL) differs from other types of acute myeloid leukemia both in terms of the spectrum of clinical symptoms, as well as cytogenetic and molecular background. Fast diagnosis of APL enables highly effective targeted therapy initiation and avoiding of serious organ/ /tissue damage (including fatal bleeding into the central nervous system). In the initial diagnostic process the most important is the rapid identification of the presence of specific cytogenetic and molecular changes involving the retinoic acid receptor alpha (RARA) gene located on the 17q21 chromosome. In patients with APL, alongside the most commonly observed translocation $t(15 ; 17)$ (q24;q21) leading to the formation of the PML-RARA fusion, several dozen variant cases have also been identified as a result of other translocations involving $R A R A$ gene with different clinical symptomatology and variable sensitivity to the targeted therapy with all-trans retinoic acid and arsenic trioxide. The paper presents the recent data concerning the epidemiology, symptomatology and accurate diagnostics methods useful for early identification of APL and immediate initiation of the molecularly targeted therapy
\end{abstract}

Key words: acute promyelocytic leukemia, epidemiology, clinical manifestation, laboratory changes, karyotype anomalies, molecular defects, targeted therapy, all-trans retinoic acid, arsenic trioxide, measurable residual disease, epidemiology, prognosis

Hematology in Clinical Practice 2021; 12, 3-4: 105-120

\section{Introduction}

In the last few years, significant progress has been made in understanding the mechanisms of leukemic transformation of hematopoietic stem cells (HSC). It has been shown that this is a stepwise process, leading to transformation of HSC to the leukemic stem cells (LSCs), as well as the disruption of the mechanisms of normal hematopoiesis. The aforementioned changes resulted in increasing peripheral blood cytopenia, leading to an increased risk of severe infections due to granulocytopenia, bleeding complications due to thrombo- cytopenia/coagulopathy and changes related to infiltration by leukemic cells of other organs [1]. The mechanism of transformation is different for each cytogenetic-molecular subtype of acute myeloid leukemia (AML). However, it is known that AML cells exhibit features of a hierarchical organization with the presence of a different sub-populations of the unmaturated cells corresponding to LSCs. For this reason, in most cases of AML there is a phenotypic and molecular diversity of individual subpopulations of leukemic cells [2]. One of the best-known types of AML is acute promyelocytic leukemia (APL) in which the primary mechanism

Address for correspondence: Krzysztof Lewandowski, Katedra i Klinika Hematologii i Transplantacji Szpiku, Uniwersytet Medyczny im. Karola Marcinkowskiego w Poznaniu, ul. Szamarzewskiego 84, 60-569 Poznań, Poland, e-mail: krzysztof.lewandowski@skpp.edu.pl

This article is available in open access under Creative Common Attribution-Non-Commercial-No Derivatives 4.0 International (CC BY-NC-ND 4.0) license, allowing to download articles and share them with others as long as they credit the authors and the publisher, but without permission to change them in any way or use them commercially. 
Table 1. Incidence of acute promyelocytic leukemia in the pediatric population by country (the percentage of all diagnosed acute myeloid leukemias) (sources $[6,7]$ )

\begin{tabular}{ll}
\hline Percentage [\%] & Country \\
\hline$<5$ & $\begin{array}{l}\text { Saudi Arabia, the Netherlands, } \\
\text { Germany, Switzerland, Sweden }\end{array}$ \\
$5-10$ & $\begin{array}{l}\text { India, Israel, Japan, South Korea, } \\
\text { Malawi, United States, Thailand, } \\
\text { Turkey, Hungary, United Kingdom }\end{array}$ \\
$10-15$ & $\begin{array}{l}\text { Bolivia, Chile, Egypt, Finland, France, } \\
\text { Malaysia, Oman, Poland, Russia, } \\
\text { Serbia, Singapore, Taiwan, Ukraine }\end{array}$ \\
& $\begin{array}{l}\text { Argentina, Australia, Belarus, Brazil, } \\
\text { China, Czech Republic, Greece, Spain, }\end{array}$ \\
& $\begin{array}{l}\text { Iran, Canada, Mexico, Nepal, Nigeria, } \\
\text { South Africa }\end{array}$ \\
& $\begin{array}{l}\text { Sudan, Tunisia, Iraq, Cuba, Nicaragua, } \\
\text { Pakistan, Venezuela, Italy }\end{array}$ \\
\hline
\end{tabular}

of leukemic transformation is reciprocal, balanced translocation, involving the retinoic acid receptor alpha subunit $(R A R A)$ gene located on chromosome 17. The most common partner gene for $R A R A$ is the acute promyelocytic leukemia protein $(P M L)$ gene located on chromosome 15 . The result of this translocation is the formation of PML-RARA fusion, leading to the inhibition of transcription of $R A R$ target genes and disruption of the function of the $P M L$ gene as the regulator of homeostasis and tumor growth suppressor [3].

\section{Epidemiology of APL}

The incidence of APL varies with the age of patients and geographic region [4]. In the pediatric population, the prevalence of APL as a subtype of AML varies between countries. A detailed summary of the incidence of APL is presented in Table 1 [5-7]. So far, the reason for such significant differences in the frequency of APL in children in individual countries, as compared to all forms of AML, has not been established (Table 1).

In adults, AML account for $70-80 \%$ of all leukemias. Approximately $10 \%$ of all AML are APL cases $[6,7]$.

\section{Influence of race and ethnicity on the incidence of APL}

The influence of race and ethnicity on the incidence of APL is under discussion. There are observed differences in incidence between populations, but there is no clear evidence that one race is more likely to suffer from APL than another. In Canada, the incidence (expressed by the incidence rate, IR) of APL is extremely low. The IR of this form of AML is only $0.083 / 100,000$ inhabitants per year. It is not known why the IR is so low. In Canada, healthcare is easily accessible in large agglomeration centers and all new cases of APL are accurately reported. Therefore, it is not possible that the incidence is underrated [8].

The IR of APL in the United States is higher than in Europe $(0.22 / 100,000$ inhabitants per year vs. $0.12 / 100,000$ inhabitants per year, respectively) $[9,10]$. The IR values for individual European countries are different. In Spain it is 0.257/100,000, in the Netherlands $0.174 / 100,000$, in Sweden $0.145 / 100,000$, and in Poland $0.023 / 100,000$ inhabitants per year [9]. The low IR for Poland, as compared to other countries, may result, among others, from low availability of modern diagnostic techniques, especially genetic and molecular ones.

The incidence of APL has been shown to be high in the Hispanic populations (descendants of Hispanics) in the United States and Latin America. According to Douer et al. [11], APL in Hispanics accounts for as much as $37.5 \%$ of all acute myeloid leukemias, while in non-Hispanics only for $6.5 \%$. A higher incidence of APL in Latin Americans was also confirmed by Yamamoto et al. For both Hispanic women and men, the IR values for APL were higher than for non-Hispanics, but the values for Hispanic women were significantly higher [10].

According to Matasar et al. [12], there are no significant differences in the incidence of APL throughout the whole life. Ethnic and racial differences in the incidence of APL are manifested primarily in particular age groups. Thus, in the 0-19 age group, the Hispanics have 1.94 times higher IR than non-Hispanic whites and 2.59 times higher IR than Africans and African Americans. In the $20-44$ age group, the Hispanics have the highest IR value. This value is 1.55 times higher, as compared to non-Hispanic whites, 2.2 times higher than in the case of Africans and African Americans, and 1.67 times higher than that of Asians. In the 45-64 age group, the IR value does not differ statistically between particular races. In the +65 age group, non-Hispanic white people have an IR of 1.85 times higher than that of the Hispanics. The people of African and African American origin have the lowest IR for APL throughout their whole life. The differences in the IR values for white non-Hispanics, Hispanics, and Asians are not statistically significant. However, the presented results do not make it possible to unequivocally state that race is a factor particularly predisposing to APL [12]. 


\section{Changes in the incidence of APL over the years}

The progress in the field of diagnostic methods used in the recent years has clearly influenced the frequency of the APL diagnosis. According to Zhang et al. [5], the frequency of APL in the years 1992-2006 increased by $5.5 \%$ each year, as compared to the previous year. It was only after 2006 that the increase in the incidence reached a relative plateau [13]. It should be mentioned that no increase in the incidence of APL was observed during this period in Canada. The cause of it remains unknown [8].

The assessment of the effect of gender on the incidence of APL has also been the subject of comprehensive analyzes. Their results have shown that gender is not related to the incidence of APL $[9,10,12]$. However, it should be mentioned that in the 16-34 and 35-54 age group in Sweden, the rate of APL in women was much higher than in men. The situation was different in the oldest age group ( +75 years of age), where the IR for men was higher than for women. A similar analysis which did not consider age showed that the incidence rate among women was higher $(0.179 / 100,000$ per year $)$ than among men $(0.113 / 100,000$ per year) [14].

Interestingly, APL is most common among middle-aged people. According to a study by Venkitachalam et al. [15], $40 \%$ of new cases in the years 2000-2014 concerned people in the 40-59 age group, while in a study by Chen et al. in the years 1975-2014, the greatest number of new cases was observed in two age groups: $30-44$ and $45-59$ years (25,46\% and $23,85 \%$, respectively). Young adults (20-39 age group) suffer from APL more often than people over 60 years of age $(32 \%$ and $28 \%$ of all cases in 2000-2014, respectively). People over 60 years of age account for approximately $28 \%$ of all new APL cases $[13,15]$.

\section{Incidence of secondary APL}

In most cases, the development of secondary acute promyelocytic leukemia occurs as a result of prior chemo- and/or radiotherapy. According to Duffield et al. [16], secondary APL accounts for $14 \%$ of all newly diagnosed APL. Most often, secondary APL develops as a result of treatment of other malignant neoplasms or as a result of chronic immunosuppression. Secondary APL usually develops within 3 years from the discontinuation of treatment. In the clinical picture, the morphology of promyelocytes and their immunophenotype do not differ from those found in de novo APL [16].

\section{Clinical symptoms of acute promyelocytic leukemia}

APL can occur at any age. However, the largest group of patients are middle-aged adults. People over 60 years of age are diagnosed with the disease less frequently. The disease occurs infrequently in patients who are younger than 10 years. In this group of patients, however, there have been described cases with atypical variants of genetic rearrangement, rarely seen in adulthood [17].

APL is characterized by a dynamic, severe and rapidly deteriorating clinical condition [18]. Common symptoms include infectious complications, hemorrhagic episodes, and weakness due to neutropenia, thrombocytopenia, and anemia, respectively. However, these symptoms are not typical of APL and may occur also in other types of AML. Other common symptoms include periodontal lesions, proliferative neutropenic ulcers of the oral mucosa with erosions and painful aphthae, impaired cellular immunity and activation of latent viral infections (i.e. the herpes zoster virus). Leukemic transformation of hematopoietic progenitor cells resulted in almost complete block of myeloid progenitors cells maturation and profound neutropenia, and thrombocytopenia in the peripheral blood. In their typical form, single blasts can also be present in the peripheral blood [17]. In the microgranular form of APL, usually associated with leukocytosis, their presence in the blood is typical. Depending on the morphology of peripheral blood cells, the following forms of the disease are distinguished with their characteristic clinical and laboratory symptoms:

\section{"Typical" (hypergranular) form (AML-M3)}

The typical form accounts for $60-70 \%$ of cases and is characterized by peripheral blood pancytopenia with distinct leukopenia which distinguishes this form from the hypogranular form. These laboratory changes may be accompanied by general symptoms, such as weakness and fatigue or weariness, as well as pale skin and symptoms of infection or hemorrhagic diathesis in the physical examination [19].

\section{Hypogranular or microgranular form (AML-M3v)}

The hypogranular form, unlike the previous one, is also accompanied by leukocytosis in the peripheral blood [20]. Patients with hyperleukocytosis may develop the symptoms of leukostasis as a result of clumping of leukemic blasts cells in 
Table 2. Comparison of selected clinical morphological subtypes of acute promyelocytic leukemia according to the French-American-British (FAB) classification system of hematological diseases (source [20])

\begin{tabular}{cc}
\hline $\begin{array}{c}\text { "Typical" form } \\
\text { (ca. 60-70\% of all cases) }\end{array}$ & $\begin{array}{c}\text { "Microgranular" form } \\
\text { (ca. 30-40\% of all cases) }\end{array}$ \\
\hline Morphological subtype & Morphological subtype \\
AML-M3 & AML-M3v \\
Hypergranular & Hipogranular/microgranular \\
promyelocytes & promyelocytes \\
Leukopenia & Leukocytosis \\
Low risk of associated & High risk of associated \\
DIC syndrome & DIC syndrome \\
\hline
\end{tabular}

*DIC syndrome - disseminated intravascular coagulation syndrome

within the small vessels and microcirculation. The result of this process are blood perfusion symptoms, especially affecting the central nervous system (CNS), and resulting in headaches and dizziness, tinnitus, focal symptoms or disturbed consciousness. They can also lead to abnormal pulmonary blood flow manifested by shortness of breath, and, in the severe form, respiratory failure. The presence of hyperleukocytosis is also associated with a higher 4 -week mortality rate $(24 \%)$, compared to the patient population without hyperleukocytosis (9\%) [21]. Rare symptoms of this form of APL include ischemic low-flow (veno-occlusive) priapism (Table 2) [22].

The clinical picture of APL also includes disseminated intravascular coagulation (DIC) syndrome. The pathophysiology of DIC in APL patients is complex and involves many mechanisms of hemostasis. The occurrence of DIC symptoms in the course of APL may lead both to the thrombosis [23], and hemorrhage. DIC syndrome is the result of nonspecific activation of plasma blood coagulation caused by the release of azurophilic cytoplasmic granules from disintegrating leukemic cells with intrinsic thromboplastic activity [24]. One of the most important inducers of DIC is the tissue factor (TF) released in large amounts from leukemic blasts. The risk of developing DIC is highest in patients with the hypogranular or microgranular variant of APL (M3v) [17]. DIC is especially common in high-risk patients with the leukocyte count $\geq 10 \mathrm{G} / \mathrm{L}$ at diagnosis, and in patients +60 years of age [19, 20, 25] (Table 3).

The presence of increased symptoms of hemorrhagic diathesis (Latin: diathesis haemorrhagica) is typical for APL. In the clinical picture, it is manifested, among others, by small ecchymoses (disseminated mucocutaneous purpura), hemor-
Table 3. Groups at risk of an unfavorable acute promyelocytic leukemia outcome (source [20])

\begin{tabular}{lcc}
\hline \multirow{2}{*}{ Risk category } & \multicolumn{2}{c}{ Stratification criteria } \\
\cline { 2 - 3 } & WBC [G/L] & PLT [G/L] \\
\hline Low risk & $\leq 10$ & $\geq 40$ \\
Intermediate risk & $\leq 10$ & $<40$ \\
High risk & $>10$ & - \\
\hline \multicolumn{2}{l}{ WBC - white blood cells (total number of leukocytes in the blood); } \\
PLT - platelets (the number of thrombocytes in the blood)
\end{tabular}

rhages and extensive bruises, or bleeding from the mucous membranes, especially from the nose (Latin: epistaxis) and gums. Less frequently, there can be observed bleeding from the gastrointestinal tract and genital tract (menorrhagia) [26].

The activation of plasma fibrinolysis mechanisms caused by the release of urokinase (u-PA) and tissue type (t-PA) plasminogen activators (PA) and lysosomal enzymes by the leukemic cells is also important. The activation of fibrinolysis accompanying the DIC symptoms may also lead to the occurrence of central nervous system complications (e.g. hemorrhagic stroke). Their occurrence often makes it impossible to undertake a decision regarding the core treatment, having an adverse effect on the prognosis in this group of patients at the same time [27-29]. It is generally accepted that in these cases, due to the high risk of potential threat to life, it is necessary to implement urgent diagnostic and therapeutic procedures and initiate anti-leukemia treatment with vitamin A derivatives, before the final diagnosis of APL is made.

In untreated cases, severe hemorrhagic diathesis occurs due to secondary coagulopathy and abnormal platelet hemostasis ("consumptive coagulopathy") in which severe thrombocytopenia and hypofibrinogenemia play a key role [20, $28]$. In the cases of APL complicated with fully decompensated DIC syndrome, the occurrence of hemorrhagic complications in the lungs and CNS often occurs even before the diagnosis and initiation of anti-leukemic treatment $[19,30$, regardless of the profile of changes in the blood coagulation tests [31].

The rapid APL progression is associated with a high incidence of early deaths (ED). In APL, ED is defined as death within the first 30 days from the moment of diagnosis [19, 32]. In the past, before the introduction of targeted therapy, patients who were untreated or on corticosteroids died within the first 30 days of diagnosis. The median survival time was less than one week [33]. Presently, de- 
spite the development of a therapy protocol based on all-trans retinoic acid (ATRA), arsenic trioxide (ATO) and anthracyclines, it is still a significant problem. It has been shown that nearly one third of patients diagnosed with APL dies within the first month, ca. $70-77 \%$ of which die within the first 7 days from the moment of diagnosis, and $30 \%$ within the same day. This makes ED the major cause of treatment failure. Despite the use of treatment with plasma derivatives and platelet concentrate, the incidence of early hemorrhagic deaths during induction therapy has not improved significantly in the recent years. It amounts to $20 \%$ and is comparable to that from 20 years ago [34]. An exception in this regard are patients treated in specialized clinical centers, where the mortality remains at the level of approximately $3-10 \%$. It probably results from easier availability of rapid genetic diagnostics and pharmacotherapy. The studies carried out so far show particular effectiveness of therapy in patients receiving treatment according to the guidelines aimed at reducing bleeding and infectious complications or the differentiation syndrome (DS). The best results are achieved with rigorous adherence to current standards of care for supportive care and monitoring of blood parameters for platelet count, fibrinogen blood concentration, and international normalized ratio (INR) and activated partial thromboplastin time (APTT) [14, 32].

The occurrence of infectious and/or hemorrhagic complications in the fully developed phase of the disease, in the pre-diagnosis period and shortly after appropriate treatment, may lead to premature death. The main cause of death in this period are most often massive hemorrhages into the critical organs (56-69\%), the most common of which are intracranial and intracerebral hemorrhages $(64 \%)$, and less frequently pulmonary hemorrhages (32\%) $[7,29,35]$. Also in these cases, most deaths occur within the first week after the diagnosis.

$12-27 \%$ of patients die due to opportunistic infections within the respiratory tract, mainly bacterial and fungal, often associated with septic shock [14]. In this group, death occurs within 3 to 39 days from the introduction of treatment; the median survival time is 21 days. For these reasons, empiric and based on germ sensitivity test results antibiotic therapy is recommended in all cases as the general standard of care in the APL management. A rare cause of ED is multiple organ failure $(6.9 \%)$ due to severe infectious and/or the DS [32, 36 . The clinical picture is rarely dominated by severe thrombotic/infarction complications (e.g. limb ischemia, myocardial ischemia, acute myocardial infarction, pulmonary embolism or cerebral venous thrombosis) as a complication of coagulopathy associated with the overexpression of proteins that promote the abnormal blood clotting, including TF or cancer procoagulant (CP) [23].

The occurrence of thromboembolic complications in patients with APL is a contraindication to invasive procedures (including central venous cannulation, lumbar puncture or bronchoscopy) [37]. In the event of thrombosis within the vascular catheters, they should be removed prior to the diagnosis of APL, immediately after the diagnosis of the disease [29].

The DS, formerly known as the retinoic acid syndrome (RAS), is also mentioned as a rare cause of early death. It represents a complex set of clinical symptoms occurring within one to two weeks after the initiation of the ATRA treatment. The data on its prevalence vary. This syndrome may affect up to $24-26 \%$ of patients, and according to some studies, up to one third of patients with APL [26]. The latest reports indicate that the risk of this syndrome exists in nearly half of the patients undergoing ATRA/ATO treatment [38]. In the course of DS, the interview and physical examination include fever, dyspnea, acute respiratory failure, hypotension, peripheral edema, and weight gain. The radiographic examination usually reveals pulmonary edema with interstitial infiltrates, and pleural and/or pericardial effusion [38]. Multiple organ failures may occur in the course of the syndrome, including liver failure, acute renal failure, and congestive heart failure $[19,20]$. These symptoms may be accompanied by hyperleukocytosis. It should be noted that severe course of DS is the cause of $15-18.5 \%$ of ED [32].

The pathogenesis of DS is not fully understood. It has been suggested that its occurrence is related to the mechanism of action of the drug and the induction of the process of blast cell differentiation. Maturing cells release pro-inflammatory cytokines responsible for triggering the systemic inflammatory response (including fever and hypotension). One of the effects of their action is an increase in the capillary permeability, leading to the systemic capillary leak syndrome (SCLS) [26]. An important role is also attributed to the regulation of the expression of adhesion molecules (including CD13), promoting the adhesion of leukocytes to capillary endothelial cells, thus initiating a local inflammatory reaction. The ability of migrating leukocytes to infiltrate tissues and the potential risk of vascular occlusion by blood cell aggregates are the basis for the development of organ 
dysfunction (including respiratory failure or renal dysfunction) [38].

\section{Symptoms of organ infiltration}

with leukemic cells

In patients with APL, the CNS may also be affected by the leukemic process, but its exact incidence is unknown. The presence of infiltration is rarely seen within the CNS de novo. The infiltration of the CNS is much more frequent in the case of extra-medullary disease [39]. The presence of neurological symptoms (such as headaches and dizziness, nausea, vomiting, visual disturbances, photophobia, phonophobia, dysarthria, convulsions, hemiplegia, unstable gait, disturbance of consciousness) is an indication for head imaging (CT contrast, MRI) to rule out the CNS bleeding. If such bleeding is excluded, APL treatment should be immediately initiated, preferably with the use of drugs penetrating the CNS.

If infiltration of the CNS is suspected, the presence of neurological symptoms at the time of diagnosis or recurrence of the disease and the results of diagnostic imaging may be an indication for performing a lumbar puncture for diagnostic and therapeutic purposes [39]. However, it is debatable if it can be performed during coagulopathy. Current guidelines allow it in high-risk patients with hyperleukocytosis during remission. It allows to avoid the development of secondary bleeding complications and minimizes the risk of implantation of leukemia cells into the CNS [40].

\section{Morphological diagnostics of acute promyelocytic leukemia}

Based on the morphological image of leukemia cells, two variants of the disease can be distinguished according to the French-American-British (FAB) classification systems of hematologic diseases. The classic form - hypergranular (M3), which accounts for 60 to $70 \%$ of APL cases, and the hypogranular - microgranular variant form (M3v) $[1,2,17]$.

The diagnosis of the hypergranular form is usually not difficult. Leukemia cells are characterized by an irregular cell nucleus and numerous, large basophilic granules and/or the presence of linearly arranged peroxidase-positive granules (Auer rods) in the cytoplasm. The diagnosis of the hypogranular form of APL is more difficult. Leukemia cells are characterized by the absence or presence of small, dispersed granules. The presence of Auer rods is also sporadic. There can be found atypical promyelocytes with bilobed nucleus in the blood smear. In the hypergranular APL form, the white blood cell count is lowered and in the hypogranular variant form, it is increased [7, 17, 41]. There has also been distinguished a version of the disease with the presence of atypical basophils, the presence of which was confirmed in one third of the patients with APL. This form of the disease is associated with a high risk of bleeding and increased mortality [42]. Depending on the different genetic variants, as compared to the classic type of APL, the morphological picture of leukemic cells is similar (with some exceptions) [17].

In cytochemistry, APL cells show a strong positive reaction to the presence of myeloperoxidase (MPO) and a positive reaction with Black Sudan B (SBB) [17]. According to the available data, $100 \%$ of APL cells show a strong MPO expression and a strong positive reaction with SBB. In $63 \%$ of cases, leukemia cells show a positive reaction to the presence of esterases (Es-chl) and in $45 \%$ of cases a positive reaction with Schiff's reagent [43].

The most common changes in the laboratory tests in patients with APL are leukopenia and thrombocytopenia $[17,44]$. In the presence of DIC syndrome, the prothrombin time and the activated partial thromboplastin time are prolonged [44].

When compared to other types of AML, laboratory test results in APL are more likely to show increased levels of fibrin/fibrinogen degradation products (FDP), D-dimers, and decreased levels of fibrinogen. In patients with APL, however, no differences in total iron binding capacity (TIBC) and transferrin levels were found, and they were within the normal range. Compared to patients with other types of AML, however, the TIBC values, blood transferrin levels, triglycerides and cholesterol levels are higher [45].

\section{Changes in the immunophenotype of blasts in acute promyelocytic leukemia}

Leukemic cells in APL are characterized by a strong expression of CD13+ and CD33+ and the lack of expression of CD34 and HLA class II antigen $[7,46]$. In the hypogranular form of APL, there is a weak expression of HLA class II and CD34+. On the other hand, the expression of $\mathrm{CD} 2+$ is more frequent. In approximately $10 \%$ of patients, regardless of the form of APL, there can be observed the expression of CD117+, CD15+, CD56+ and $\mathrm{CD} 64+[17,25,47]$. The expression of the CD2+ antigen is often accompanied by the expression of $\mathrm{CD} 34+$. The $\mathrm{CD} 2+$ expression carries a higher risk of death and a lower 5-year overall survival. 
The presence of the CD34 antigen on leukemic blasts is also associated with poor prognosis [25].

According to the latest recommendations, the use of CD9+/CD11b +/HLA class II (-) antigens in the diagnosis of APL enables the diagnosis of APL with sensitivity amounting to $85 \%$ and specificity amounting to $95 \%$. In turn, the combination of CD34+/CD117+/HLA class II (-) antigens enables the diagnosis of APL with the sensitivity of $39 \%$ and the specificity of $92 \%$. Similarly, the diagnostic use of a CD11b +/HLA class II (-) antigen combination enables the diagnosis of the disease with the sensitivity and specificity equal to $80 \%$ [47]. Another study, where the cut-off was $20 \%$, showed that the combination of CD117+/CD13+/ $/ \mathrm{CD} 56+/ \mathrm{CD} 64+$ antigens and MPO enables the diagnosis of APL with the sensitivity of $91.7 \%$ and the specificity of $93.1 \%$, as compared to other types of AML without the expression of the HLA antigen class II [48].

\section{Genetic basis of APL}

In most cases, APL results from a reciprocal, balanced translocation of $\mathrm{t}(15 ; 17)(\mathrm{q} 24 ; \mathrm{q} 21)$ involving the promyelocytic leukemia protein $(P M L)$ gene on chromosome 15q24 and the retinoid acid receptor alpha unit $(R A R A)$ gene on chromosome $17 \mathrm{q} 21$ [49]. In the case of the $P M L$ gene, the translocation area covers $35 \mathrm{~kb}$ and 9 exons, with the sequences $7 \mathrm{a}, 7 \mathrm{~b}, 8 \mathrm{a}$ and $8 \mathrm{~b}$ within exons 7 and 8 , respectively. For the $R A R A$ gene, the size of the translocated material is $7.5 \mathrm{~kb}$. In this case, 9 exons of the RARA gene are translocated, with the start codon within exon 2 and the stop codon within exon 9 , encoding the sequence of 6 domains (A, B, $\mathrm{C}, \mathrm{D}, \mathrm{F})$ of the RARA protein $[50,51]$. In the case of the RARA gene, the break point cluster region is in intron 2. Within the $P M L$ gene, three break point cluster regions (bcr) have been identified: bcr1 in intron 6 , bcr2 in exon 6 and bcr3 in intron 3 . The cases with a break point cluster region within bcr1 and bcr3 account for 90-95\% of all the cases reported for APL patients [52]. About 30\% of APL patients also show other chromosomal abnormalities, including trisomy 8 [53]. The coexistence of other molecular defects with the $\mathrm{t}(15 ; 17)(\mathrm{q} 24 ; \mathrm{q} 21)$ translocation have also been confirmed, among others, the FMS-like tyrosine kinase 3 (FLT3) gene mutation detected in 30-33\% of APL patients (including FLT3-ITD in 13\% of cases), WT1 mutation in about $14 \%$ and NRAS in about $7-10 \%[54,55]$.

So far, 17 new variant translocations involving the $R A R A$ gene have been detected in patients with
APL. Their detailed molecular characteristics and the sensitivity to ATRA and ATO treatment are presented in Table 4 [52, 56, 57].

\section{Proceedings in the event of suspicion of APL}

According to the latest recommendations, if APL is suspected, treatment with ATRA should be started immediately. At the same time, molecular tests should be performed to confirm the presence/absence of the PML-RARA fusion and/or the translocation $\mathrm{t}(15 ; 17)$. The presence of leukopenia or leukocytosis in the variant form of disease, the identification of promyelocytes in the peripheral blood smear, and blood coagulation disorder with the clinical and laboratory features of consumption coagulopathy, makes the diagnosis of APL very probable $[56,57]$.

The administration of ATRA induces the maturation and differentiation process of leukemic cells by changing the conformation of the $P M L-R A R A$ fusion protein. A direct connection of ATRA to the RARA protein leads to the release of corepressors and cofactors of the process of the activation of the vitamin A-dependent gene(s) transcription process. Their result is the induction of the promyelocyte differentiation, a decrease in promyelocytes content in the bone marrow and in the peripheral blood, with a significant reduction in the severity of coagulopathy. The recommended daily dose of ATRA is $45 \mathrm{mg} / \mathrm{m}^{2}$ of body surface area, administered orally in two equally divided doses. In patients with hepatic and/or renal insufficiency, the daily ATRA dose should be reduced to $25 \mathrm{mg} / \mathrm{m}^{2}$ body surface area [58].

\section{Remission-inducing treatment}

It is possible to use one of several remission induction schemes in patients with APL. One of them is based on chemotherapy with the use of full doses of anthracyclines (TxA) in combination with ATRA.

The use of combination therapy is very effective and allows to achieve complete remission of the disease even in $90-95 \%$ of patients. Moreover, it has been shown that the use of the combination therapy with ATRA + TxA significantly reduces the frequency of relapses, as compared to monotherapy with ATRA or TxA alone [59]. Combination therapy has also been shown to be more effective than the crossover method [60]. An alternative protocol for the induction treatment is the AIDA regimen (ATRA + idarubicin). In this regimen, 
Hematology in Clinical Practice 2021, vol. 12, no. 3-4

Table 4. Clinical and cytogenetic and molecular characteristics of atypical forms of acute myeloid leukemia (sources $[52,56,57])$

\begin{tabular}{|c|c|c|c|c|c|}
\hline $\begin{array}{l}\text { Variant of the } \\
\text { fusion with } \\
\text { RARA }\end{array}$ & $\begin{array}{l}\text { Translocation/ } \\
\text { /chromosomal } \\
\text { variant }\end{array}$ & Gene function & $\begin{array}{l}\text { Clinical } \\
\text { symptoms } \\
\text { DIC }\end{array}$ & $\begin{array}{l}\text { Sensitivity } \\
\text { to ATRA }\end{array}$ & $\begin{array}{l}\text { Sensitivity } \\
\text { to ATO }\end{array}$ \\
\hline ZBTB16-RARA & $t(11 ; 17)(q 23 ; q 21)$ & $\begin{array}{l}\text { ZBTB16 expression is associated with } \\
\text { a number of cellular processes including } \\
\text { differentiation, apoptosis, proliferation }\end{array}$ & Yes & Resistant & Resistant \\
\hline NPM1-RARA & $t(5 ; 17)(q 35 ; q 21)$ & $\begin{array}{c}\text { NPM1 regulates the activity of many tumor } \\
\text { growth suppressors, including MDM2, p53, } \\
\text { and ARF. Participates in ribosome biogenesis, } \\
\text { regulates protein synthesis by interacting } \\
\text { with c-myc }\end{array}$ & Yes & Sensitive & No data \\
\hline STAT5B-RARA & $\operatorname{der}(17)$ & $\begin{array}{l}\text { Factor involved in signaling the JAK-STAT } \\
\text { path, participates in the stimulation } \\
\text { of cytokine and hormone dependent } \\
\text { growth and differentiation }\end{array}$ & Yes & Resistant & Resistant \\
\hline IRF2BP2-RARA & $\mathrm{t}(1 ; 17)(\mathrm{q} 42 ; \mathrm{q} 21)$ & $\begin{array}{l}\text { IRF2BP2 protein (interferon regulatory factor } \\
2 \text { binding protein } 2 \text { ) is responsible for the } \\
\text { regulation of the transcription of genes } \\
\text { dependent on type I interferon }\end{array}$ & $\begin{array}{l}\text { In some } \\
\text { cases }\end{array}$ & Sensitive & Sensitive \\
\hline FIP1L1-RARA & $t(4 ; 17)(q 12 ; q 21)$ & $\begin{array}{l}\text { Encodes a component of the complex } \\
\text { involved in mRNA trimming and } \\
\text { polyadenylation (mRNA processing) }\end{array}$ & No & Sensitive & No data \\
\hline BCOR-RARA & $t(X ; 17)(p 11 ; q 21)$ & $\begin{array}{c}\text { BCOR interacts with the BTB-POZ domain } \\
\text { of the BCL- } 6 \text { protein causing the repression } \\
\text { of its functions }\end{array}$ & $\begin{array}{l}\text { In some } \\
\text { cases }\end{array}$ & Sensitive & Insensitive \\
\hline TBLR1-RARA & $t(3: 17)(q 26: q 21)$ & $\begin{array}{l}\text { TBLR1 gene (transduction } \beta \text {-like } 1 \text { X-linked } \\
\text { receptor 1) plays a role in the activation of } \\
\text { transcription, and the proteins expressed as } \\
\text { a result of its action are an important element } \\
\text { of the nuclear corepressor receptor (N-CoR) } \\
\text { and histone deacetylase } 3 \text { (HDAC } 3 \text { ) }\end{array}$ & No data & Resistant & Sensitive \\
\hline STAT3-RARA & der17 & $\begin{array}{c}\text { Factor involved in the JAK-STAT pathway } \\
\text { signaling, participates in the stimulation } \\
\text { of cytokine and hormone dependent } \\
\text { growth and differentiation }\end{array}$ & No data & Resistant & No data \\
\hline NUMA1-RARA & $\mathrm{t}(11 ; 17)(\mathrm{q} 13 ; \mathrm{q} 21)$ & $\begin{array}{l}\text { NUMA1 is involved in the mitotic process } \\
\text { by interacting with microtubules during } \\
\text { the formation of the mitotic spindle }\end{array}$ & Yes & Sensitive & No data \\
\hline PRKAR1A-RARA & $\begin{array}{l}\mathrm{t}(17 ; 17)(\mathrm{q} 21 ; \mathrm{q} 24) \\
\text { del(17)(q21; q24) }\end{array}$ & $\begin{array}{c}\text { One of the main factors of type } 1 \text { protein ki- } \\
\text { nase A, the main mediator of signal } \\
\text { transmission via cAMP }\end{array}$ & No & Sensitive & Sensitive \\
\hline NABP1-RARA & $t(2 ; 17)(q 32 ; q 21)$ & $\begin{array}{c}\text { NABP1 (nucleic acid binding protein 1) plays } \\
\text { an important role in the response to DNA } \\
\text { damage and the processes of maintaining } \\
\text { genome stability }\end{array}$ & No & Sensitive & No data \\
\hline GTF2I-RARA & $\mathrm{t}(7 ; 17)(q 26 ; q 21)$ & $\begin{array}{l}\text { GTF21 (general transcription factor Ili) } \\
\text { plays an important role in the processes } \\
\text { of transcription, signal transmission } \\
\text { by growth factors, and the function } \\
\text { of the immune system }\end{array}$ & Yes & resistant & resistant \\
\hline FNDC3B-RARA & $t(3 ; 17)(q 26 ; q 21)$ & $\begin{array}{l}\text { Fibronectin type III domain containing } 3 \mathrm{~B} \\
\text { gene probably participates in the positive } \\
\text { regulation of adipogenesis }\end{array}$ & No data & Sensitive & Sensitive \\
\hline $\begin{array}{l}\text { ADAMTS17- } \\
\text {-RARA }\end{array}$ & $\begin{array}{l}\text { Comment: ADMTS17 } \\
\text { gene (ADAM metallo- } \\
\text { peptidase with throm- } \\
\text { bospondin type } 1 \text { mo- } \\
\text { tif } 17 \text { ) is localized on } \\
\text { chromosome } 15 q 26.3\end{array}$ & Unknown & No data & Sensitive & No data \\
\hline TFG-RARA & $\begin{array}{c}\mathrm{t}(3 ; 14 ; 17) \\
(\mathrm{q} 12 ; \mathrm{q} 11 ; \mathrm{q} 21)\end{array}$ & $\begin{array}{l}\text { TFG gene participates in the trafficking from } \\
\text { endoplasmic reticulum to the Golgi regulator }\end{array}$ & No & Sensitive & No data \\
\hline Unknown RARA & $\mathrm{t}(4 ; 17)(\mathrm{q} 12 ; \mathrm{q} 21)$ & - & No data & Resistant & No data \\
\hline NUP98-RARA & $\operatorname{der} 17$ & $\begin{array}{l}\text { NUP98 codes the nuclear pore complex (NPC) } \\
\text { protein, regulates the nuclear-cytoplasmic } \\
\text { transport of proteins and mRNAs }\end{array}$ & Yes & No data & No data \\
\hline
\end{tabular}


ATRA is administered at a dose of $45 \mathrm{mg} / \mathrm{m}^{2} /$ day and idarubicin (IDA) $12 \mathrm{mg} / \mathrm{m}^{2}$ intravenously on days $2,4,6$ and 8 of the treatment cycle. The administration of ATRA is continued until complete remission is achieved in the peripheral blood and bone marrow. The occurrence of side effects requires a reduction in the ATRA dose to $25 \mathrm{mg} /$ $/ \mathrm{m}^{2} /$ day. Similarly, in patients +70 years old, it is recommended to reduce the number of IDA administrations to 3 days - i.e. on days 2,4 and 6 of the treatment cycle $[61,62]$. Recently, ATO has been applied in the induction treatment of APL. In lower concentrations, the drug induces the process of differentiation of leukemic cells, and in high concentrations, it induces the process of their apoptosis. The mechanism of action of ATO differs from that of ATRA. ATO binds directly to the PML fragment of the PML-RARA fusion protein, the consequence of which is the attachment of the ubiquitin-like protein SUMO to PML, initiating the process of SUMOylation and subsequent degradation of the PML-RARA protein. Theoretically, the use of ATO may eradicate clonogenic leukemia initiating cells (LIC) by stimulating their differentiation process. It should be remember that LIC constitute a small subpopulation of leukemic blasts, able to relapse even in remission of the disease [7]. The aforementioned properties of ATO have become the reason for an increase in its use in the treatment of patients with a relapse of the disease, as well as patients with the refractory form of APL. Monotherapy with ATO makes it possible to achieves a similar percentage of complete remissions as in the case of combined ATRA and TxA therapy [57]. The effectiveness of the induction treatment of combination therapy with ATRA and IDA was also compared with that of combination therapy with ATRA + ATO. In the latter case, the drugs were used in the following doses: ATO $15 \mathrm{mg} /$ $/ \mathrm{kg}$ bw intravenously and ATRA $45 \mathrm{mg} / \mathrm{m}^{2} /$ day orally. It turned out that this therapy significantly improved the overall survival of patients with APL. The hematological toxicity also turned out to be low, having a direct impact on the risk of neutropenic infections. However, combination therapy turned out to be associated with a higher incidence of symptoms of hepatotoxicity, as compared to the standard ATRA and TxA induction regimen. The use of combined ATRA + ATO therapy is also possible in the elderly with comorbidities, including cardiac conditions which are a contraindication to the use of anthracyclines [63].

\section{Consolidation treatment [64]}

The most common form of consolidation treatment is the administration of $2-3$ cycles of treatment with TxA + ATRA [57]. Its application enables molecular remission (MR) in $90-99 \%$ of patients. Autologous hematopoietic cell transplantation or reinduction with ATO may be considered in patients in whom the PML-RARA transcript is still detectable in PCR after the consolidation treatment [65].

\section{Post-remission maintenance treatment}

Obtaining MR with the consolidation treatment does not protect against relapse. To prevent relapse in patients treated with the ATRA + + TxA regimen, two cycles of the ATO + ATRA combination treatment are recommended. If, for some reason, this is not possible, the maintenance therapy consists of a triple therapy: mercaptopurine (MP), methotrexate (MTX) and ATRA [23]. Each maintenance treatment cycle begins between 2 and 4 weeks after the last cycle of consolidation therapy, as soon as the neutrophil count increases $\geq 1,0 \mathrm{G} / \mathrm{L}$, and the platelet counts is $\geq 100 \mathrm{G} / \mathrm{L}$. The treatment with ATRA + ATO lasts 12 weeks and the treatment regimen is as follows:

- ATO: $0.15 \mathrm{mg} / \mathrm{kg} /$ day intravenously, 5 days a week, with a 2-day break. The treatment is continued for 4 weeks followed by a 2 -week break; - ATRA: $45 \mathrm{mg} / \mathrm{m}^{2} /$ day, orally, in two divided doses for 2 weeks daily, followed by a 2 -week break. In order to avoid the symptoms of pseudotumor cerebri in people under 20 years of age, the ATRA dose should be reduced to $25 \mathrm{mg} /$ $/ \mathrm{m}^{2} /$ day.

\section{Treatment of APL relapse}

Relapse after complete remission is usually defined as hematological, extra-medullary, or molecular disease reoccurrence. A hematological relapse should be diagnosed when the number of blasts or atypical promyelocytes in the marrow is $>20 \%$ or when the number of blasts or atypical promyelocytes in two bone marrow samples taken one week apart is $>5 \%$. The confirmation of APL relapse in these cases is the presence of the $P M L$ $-R A R A$ fusion. An extra-medullary relapse should be diagnosed when the leukemic infiltrates and/ /or leukemic cells are found in the cerebrospinal 
fluid or other tissues or organs. Extra-medullary APL relapse should also be confirmed by immunophenotyping and/or molecular tests. A molecular APL relapse is defined as the reappearance of a PML-RARA positivity in two consecutive bone marrow samples taken at any time after the end of treatment. The persistence of a positive PCR result for PML-RARA after the end of treatment is the criterion of resistance to the treatment [20, 29]. In patients with persistent residual disease at the molecular level or molecular APL relapse, emergency treatment, including hematopoietic stem cell transplantation, should be introduced immediately. In these cases, ATO + ATRA therapy should be considered if ATRA + TxA/idarubicin were used as the first line of treatment. If ATO + ATRA was used as the 1st line of treatment, a treatment consisting of ATRA + TxA (idarubicin) can be introduced. Therapy with anti-CD33 monoclonal antibodies (GO, gemtuzumab ozogamicin) may also be considered.

\section{Results of clinical trials in the treatment of acute promyelocytic leukemia}

The introduction of ATRA to the treatment algorithms has significantly improved the long term outcome of APL patients. It is especially evident over the past two decades. Its use reduced the 5 -year mortality from $82 \%$ to $36 \%$. This was made possible thanks to the use of a combination therapy involving the administration of ATRA, cytarabine (Ara-C), ATO and anthracyclines [daunorubicin -(DNR) or IDA]. The use of combined therapy resulted in complete remissions (CR) rate $90-95 \%$, and the cure rate exceeded $80 \%$. Despite high CR rates, treatment-related mortality and relapse frequency were still high (10\% and $20-30 \%$, respectively). The aforementioned data necessitated the search for new drug combinations, the use of which will enable not only the achievement of CR, but also reduce the treatment related mortality and the frequency of APL relapses [66, 67].

Recently, the use of the aforementioned oral form of arsenic called the Realgar-Indigo naturalis formula (RIF) has been very popular. The results of its application were summarized by Sasijareonrat et al. in 2020 [68], based on a systematic review of MEDLINE and EMBASE databases. The metaanalysis included only the results of randomized and control group trials. The final analysis included 482 patients, 258 treated with RIF and 224 patients treated with the classic intravenous form of ATO. The chances of achieving CR were numerically higher in the group receiving the oral form of the drug, but this difference was not statistically significant. Also, the 30-day mortality, event-free survival (EFS), and overall survival (OS) rates were higher in the RIF-treated patients. However, these differences were not statistically significant. Interestingly, the risk of APL recurrence was higher in the group treated with the oral form of arsenic. Also in this case, the difference was not statistically significant. The incidence of side effects did not differ significantly, as well. These results may indicate that the use of ATRA in combination with the oral form of arsenic in patients with low to intermediate risk of an unfavorable APL course is at least as effective as intravenous administration of the drug [68].

A meta-analysis published in 2016 compared five previously used de novo treatment strategies of APL [69]. The efficacy of the following therapeutic strategies was assessed: ATO + ATRA, RIF with ATRA, ATRA + anthracycline, ATO and ATRA. The assessment was based on the results of 14 randomized controlled trials including 1407 newly diagnosed APL patients in the years 1998-2015 (ATRA + ATO, $\mathrm{n}=537$, RIF + ATRA, $\mathrm{n}=117$, ATRA + TxA, $\mathrm{n}=297$, ATRA, $\mathrm{n}=346$ and ATO, $\mathrm{n}=110) .98$ cases $(7 \%)$ who had died before the 30 th day from the initiation of treatment were excluded from the analysis. The analysis showed no significant differences between the assessed treatment regimens in terms of the percentage of the achieved CR. Taking into account the cases of early death and the percentage of achieved CRs, the most effective treatment method was the combination of ATO-ATRA and RIF-ATRA, followed by ATRA + TxA, and monotherapy with ATO. The lowest efficacy of treatment was confirmed with the use of ATRA as monotherapy. The evaluation of long-term treatment outcomes showed that the use of ATO-RIF in combination with ATRA improves OS and EFS, as compared to ATRA in combination with an anthracycline in patients with low and medium risk. On the basis of this observation, the authors of the study concluded that the treatment regimen of ATO in combination with ATRA and RIF in combination with ATRA may be considered optimal in the treatment of newly diagnosed cases of APL and should be recommended as the first-line therapy [69].

Abaza et al. [68] demonstrated that the combination of ATRA with ATO is better than the administration of ATRA in combination with chemotherapy in patients with newly diagnosed APL with low or moderate risk of an unfavorable course of the disease. It also turned out that adding GO to 
the above-mentioned therapy regimen improved the effectiveness of treatment in high-risk and low-risk patients in the case of leukocytosis in the course of ATRA treatment (CR rate $96 \%$ ). The mortality in this group of patients was estimated at $4 \%$. It also turned out that as many as $45 \%$ of low-risk patients required the administration of GO or IDA due to leukocytosis during the ATRA treatment. After a mean follow-up of 47.6 months, the 5-year progression free survival (PFS), relapse free survival (RFS) and S were $85 \%, 96 \%$, and $88 \%$, respectively. This study confirmed the purposefulness of using ATRA and ATO with or without GO in patients with newly diagnosed APL.

Another meta-analysis conducted by Li et al. in 2017 [69], assessed the effectiveness of combination chemotherapy in patients with APL. The study group consisted of 7566 newly diagnosed patients, and the median follow-up time of the evaluated patients was 49.24 months (the follow-up ranged from 12 to 121 months). After the induction treatment, $89.77 \%$ of patients achieved CR in a mean period of 38.25 days. The mortality during the induction of remission was estimated at $6.34 \%$. The $\mathrm{CR}$ rate after induction of ATRA, ATO and DNR was determined to be $96.16 \%$, for ATRA-DNR it was $94.3 \%$, for ATRA-DNR-cytarabine it was $92 \%$ and for ATRA-idarubicin it amounted to $91.2 \%$. The total relapse rate was estimated at $14.4 \%$. The analysis confirmed an inverse relationship between the number of leukocytes and the percentage of the obtained CRs. In this analysis, the 5-year OS and 5-year RFS were $86.41 \%$ and $75.42 \%$, respectively [67].

It should be mentioned that the results of randomized clinical trials do not always reflect the results of treatment in real life conditions. Sobas et al. analyzed 283 unselected patients with APL treated in 20 Polish hematology centers in the years 2005-2017. All patients were treated according to the ATRA-based PETHEMA protocol regimen in combination with anthracycline chemotherapy. The 4 -year OS rate was $67 \%$ and the EFS rate was $4 \%$. The ED rate was estimated at $20.1 \%$, and the pretreatment death rate was $3.5 \%$ (10 patients). The main causes of ED were hemorrhages $(45.6 \%)$, infections (17.5\%), and the DS (14\%). Out of 273 treated patients, $214(78.4 \%)$ achieved hematological remission. Two patients $(0.7 \%)$ were resistant to the treatment. $47(17.2 \%)$ patients could not be assessed due to ED. For $6(3.7 \%)$ patients, response data could not be obtained. The conducted analyzes showed that the factors predisposing to ED and OS were: the patients' performance status assessed according to the Eastern Cooperative
Oncology Group (ECOG) scale $>2,+60$ years of age and the occurrence of bleeding before the start of treatment. An additional factor that had a negative impact on EFS was the number of white blood cells $>10 \mathrm{G} / \mathrm{L}$. This study confirmed that the main factor influencing the end result of the APL treatment was early mortality [36]. The introduction of ATRA and ATO in the classic form of APL significantly improved the early results of the APL treatment. A problem which has not been solved in this group of patients is the relatively high frequency of disease relapses, especially among high-risk patients, and the high mortality in the case of relapse in patients previously treated with ATO. Another problem is the relatively frequent (20-25\%) occurrence of the DS, directly related to the treatment used [38]. For these reasons, patients with risk factors predisposing them for relapse should be eligible for autologous stem cell transplantation (auto-SCT). Recently published registry data show that the post-transplant course of the disease in patients undergoing auto-SCT in the second complete hematological remission is better than in the case of allogeneic hematopoietic cell transplantation (allo-SCT), both in terms of leukemia free survival (LFS) as well as OS [70].

In some cases, achieving molecular remission in APL is difficult and requires additional treatment. An excellent example is obtaining MR in a young patient with the ider(17)(q10)t(15;17)(q22;q21) variant of the disease in whom $\mathrm{CR}$ was confirmed after one month of treatment with ATRA + ATO, with negative $P M L-R A R A$ fusion test result after adjuvant DNR + cytosine arabinoside therapy [71].

\section{Measurable residual disease assessment}

Measurable residual disease (MRD) is a term that reflects the presence of persistent malignant cells after treatment that are not detectable by cytomorphological evaluation methods. MRD determines the number of leukemic cells in proportion to normal cells and is usually in the range of $1: 10^{4}$ to $1: 10^{6}$. By comparison, a standard disease assessment using morphological microscopic techniques detects one leukemia cell per 20 white blood cells [72]. The MRD assessment also concerns patients who achieved complete hematological remission defined as a decrease in the percentage of blast cells in the bone marrow smear $<5 \%$, the absence of Auer rods/promyelocyte morphology; the absence of extramedullary leukemia foci and restoration of normal hematopoiesis in all hematopoietic cell lines [73]. 
One of the most widely used techniques to evaluate MRD is multicolor flow cytometry (MFC). The following characteristics of leukemia cells can be assessed by flow cytometry: sidescattered light (SSC), forward scatter (FSC) and cluster differentiation molecules (CD), as well as cytoplasmatic cluster differentiation molecules (cCD). It is possible thanks to the use of monoclonal antibodies coupled with various fluorescent dyes [74]. Distinguishing leukemia cells from normal hematopoiesis cells is possible due to the presence of an aberrant set of surface/cytoplasmic antigens on leukemic cells - the leukemia-associated immunophenotype (LAIP). If LAIP cannot be used, it is also possible to identify MRD by comparing the phenotype of the patient's marrow cells with the phenotype of normal marrow cells and selecting a population of cells with a different distribution of $\mathrm{CD}$ markers expression. After the identification of the patient-specific immunophenotype of APL cells, further monitoring of MRD is possible at any stage of the treatment [75]. The MFC method allows to obtain quick results with relatively low evaluation costs. The sensitivity of this method ranges from $10^{-3}$ to $10^{-5}$. Unfortunately, the sensitivity of MRD monitoring with MFCs is often reduced due to the lack of differences in the expression of individual antigens on leukemia cells and their corresponding normal cells. Another problem affecting the reliability of the MFC MRD assessment is, among others, immunophenotypic instability of the leukemic clone which leads to the formation of several cell subpopulations with different phenotypes (resistance, disease relapse). This observation contributed to the use of a wide panel of antibodies in these cases. Despite its common use, the disadvantage of the MFC is also its lack of standardization in APL cases. It makes it impossible to compare MRD levels between particular laboratories, and to draw general conclusions about the relationship between the MRD levels and the risk of disease relapse.

The $P M L-R A R A$ transcript assessment in total RNA originated from the bone marrow cells enables the diagnosis of molecular APL remission (molecular remission) [76]. MRD monitoring in acute myeloid leukemia - both at the cytometric and molecular level, is of great practical importance. The presence of MRD is an independent prognostic factor and correlates with the risk of disease relapse [72, 77, 78]. A high MRD level after the completion of induction therapy is associated with a poorer prognosis [79]. MRD assessment also makes it possible to recognize an imminent APL relapse and to initiate rescue therapy early [80]. Currently, attempts are being made at standardizing the MRD assessment using highly sensitive techniques including real-time polymerase chain reaction (RQ-PCR), reverse transcription polymerase chain reaction (RT-PCR), droplet digital PCR (ddPCR) and next generation sequencing (NGS) $[76,78,81]$. Unfortunately, the standardization of the above-mentioned methods has not been fully carried out so far. For this reason, their introduction into routine clinical practice remains a challenge. PCR and ddPCR tests are time-consuming (e.g. in the case of RT-PCR about two days), laborious and require appropriately trained personnel. However, molecular MRD assessment is widely used in laboratory monitoring of patients with APL. The preferred material for MRD monitoring is bone marrow mRNA. It has been shown that the analysis of peripheral blood mRNA samples is characterized by much less sensitivity [82]. Molecular MRD assessment is applicable in approximately $95 \%$ of APL cases positive for the PML-RARA fusion $[82,83]$. Regular assessment of its presence is the basis of molecular monitoring of APL relapse after the end of treatment [77]. However, confirming its presence at the molecular level is not always associated with a rapid relapse of the disease. Some of the patients remain in long-term remission of the disease despite the detectable PML-RARA transcript [84]. MRD monitoring also enables making optimal therapeutic decisions, minimizing the possible risk of over-treatment and avoiding symptoms of excessive toxicity. The PETHEMA research group distinguished three groups at risk of an unfavorable course of the disease depending on the MRD level: high with MRD $\geq 0.1 \%$, intermediate with MRD $<0.1 \%$ and $\geq 0.01 \%$, low with MRD $<0.01 \%$. According to the guidelines of the National Comprehensive Cancer Network (NCCN Guidelines ${ }^{\circledR}$ from October 2020), a test confirming the achievement of molecular remission should be performed using PCR and the material obtained from the bone marrow biopsy after consolidation is completed. Post-treatment follow-up should also include the evaluation of MRD by the means of PCR every 3 months for 2 years to detect molecular APL recurrence. It particularly applies to high-risk patients over the age of 60 , patients with long breaks in consolidation therapy, and those who do not tolerate maintenance therapy. Clinical experience shows that the risk of disease relapse in low-risk patients who are in molecular remission after the consolidation is complete is low. Therefore, MRD monitoring may not be necessary 
in these cases. If the test result is positive, the test has to be repeated within 2-4 weeks. If the second test is also positive, molecular recurrence of APL should be recognized and appropriate treatment initiated. If the result of the second test is negative, it is recommended to monitor the presence of MRD every 3 months for 2 years. The test should be carried out in the same laboratory to ensure the same level of sensitivity [85]. MRD monitoring with NGS enables the examination of not only specific transcripts, but also potentially other $R A R A$ fusion transcripts [76]. The NGS method allows quantitative assessment of the MRD level, and thus an insight into the dynamics of MRD decrease/increase in patients with the classic form of APL and in the case of variant forms. Tests based on the detection of fusion show greater sensitivity, compared to tests based on the detection of specific fusion transcripts by means of PCR. It stems from the fact that leukemia cells have different expression levels and therefore different levels of certain transcripts. This can lead to an overestimation or an underestimation of the MRD level. Different patients may have different expression levels of certain fusion transcripts, which affects the sensitivity of the MRD assays [76]. However, the high cost of the NGS studies is also important [86]. An alternative method of quantifying the bcr1 and bcr3 transcripts of the PML-RARA fusion is the ddPCR. It shows a similar or higher sensitivity, as compared to the previously described PCR techniques. The main advantage of this method is absolute quantification and the ability to assess MRD when it is below the detection limit for other PCR methods [81].

\section{Acknowledgments}

The paper was written as a part of the course "Introduction to scientific research" during full-time studies in the second year of studies at the Medical Faculty of Poznan University of Medical Sciences in the academic year 2020/2021. We would like to thank Katarzyna Lewandowska for editing and proofreading the final version of the manuscript.

\section{Conflict of interest}

None.

\section{Funding}

None.

\section{References}

1. De Kouchkovsky I, Abdul-Hay M. Acute myeloid leukemia: a comprehensive review and 2016 update. Blood Cancer J. 2016; 6(7): e441, doi: 10.1038/bcj.2016.50, indexed in Pubmed: 27367478.

2. Arnone M, Konantz M, Hanns P, et al. Acute myeloid leukemia stem cells: the challenges of phenotypic heterogeneity. Cancers (Basel). 2020; 12(12), doi: 10.3390/cancers12123742, indexed in Pubmed: 33322769.

3. Noguera N, Catalano G, Banella C, et al. Acute promyelocytic leukemia: update on the mechanisms of leukemogenesis, resistance and on innovative treatment strategies. Cancers (Basel). 2019; 11(10): 1591, doi: 10.3390/cancers11101591, indexed in Pubmed: 31635329.

4. Brunner AM, Kim P, Sadrzadeh H, et al. Clustered incidence of adult acute promyelocytic leukemia. Leuk Res. 2018; 74: 47-50, doi: 10.1016/j.leukres.2018.09.008.

5. Zhang L, Samad A, Pombo-de-Oliveira MS, et al. Global characteristics of childhood acute promyelocytic leukemia. Blood Rev. 2015; 29(2): 101-125, doi: 10.1016/j.blre.2014.09.013, indexed in Pubmed: 25445717.

6. Seferyńska I. [Incidence of acute myeloid and lymphoblastic leukemias in adults in Poland between 2004-2010] [Article in Polish]. Hematologia. 2015; 6(Suppl B): 1-40, doi: 10.5603/ Hem.2015.0044.

7. Podhorecka M, Macheta A. Ostra białaczka promielocytowa nowe podejście do patogenezy choroby i terapii różnicującej. Postepy Hig Med Dosw. 2013; 67: 1083-1089.

8. Paulson K, Serebrin A, Lambert P, et al. Acute promyelocytic leukaemia is characterized by stable incidence and improved survival that is restricted to patients managed in leukaemia referral centres: a pan-Canadian epidemiological study. Br J Haematol. 2014; 166(5): 660-666, doi: 10.1111/bjh.12931, indexed in Pubmed: 24780059 .

9. Dinmohamed AG, Visser O. Incidence of acute promyelocytic leukemia across Europe: results of RARECAREnet - a population-based study. Stem Cell Investig. 2019; 6: 37, doi: 10.21037/ sci.2019.10.03, indexed in Pubmed: 31853453.

10. Yamamoto JF, Goodman MT. Patterns of leukemia incidence in the United States by subtype and demographic characteristics, 1997-2002. Cancer Causes Control. 2008; 19(4): 379-390, doi: 10.1007/ s10552-007-9097-2, indexed in Pubmed: 18064533.

11. Otero JC, Santillana S, Fereyros G. High frequency of acute promyelocytic leukemia among Latinos with acute myeloid leukemia [letter; comment]. Blood. 1996; 88(1): 377-377, doi: 10.1182/ blood.v88.1.377a.377a.

12. Matasar MJ, Ritchie EK, Consedine N, et al. Incidence rates of acute promyelocytic leukemia among Hispanics, blacks, Asians, and non-Hispanic whites in the United States. Eur J Cancer Prev. 2006; 15(4): 367-370, doi: 10.1097/00008469-200608000-00011, indexed in Pubmed: 16835508.

13. Chen $Z$, Mai W, Li Z, et al. The epidemiological trend of acute promyelocytic leukemia over past four decades: a population-based analysis. Leuk Lymphoma. 2019; 60(14): 3470-3481, doi: 10.1080 /10428194.2019.1639164, indexed in Pubmed: 31305195.

14. Lehmann S, Ravn A, Carlsson L, et al. Continuing high early death rate in acute promyelocytic leukemia: a population-based report from the Swedish Adult Acute Leukemia Registry. Leukemia. 2011; 25(7): 1128-1134, doi: 10.1038/leu.2011.78, indexed in Pubmed: 21502956. 
15. Venkitachalam R, Szabo A, Guru Murthy GS. Population-level outcomes of pediatric acute promyelocytic leukemia in the United States. J Pediatr. 2020; 223: 114-119.e5, doi: 10.1016/j. jpeds.2020.04.007, indexed in Pubmed: 32482395.

16. Duffield AS, Aoki J, Levis M, et al. Clinical and pathologic features of secondary acute promyelocytic leukemia. Am J Clin Pathol. 2012; 137(3): 395-402, doi: 10.1309/AJCPE0MVOYTWLUUE, indexed in Pubmed: 22338051.

17. Adams J, Nassiri M. Acute promyelocytic leukemia: a review and discussion of variant translocations. Arch Pathol Lab Med. 2015; 139(10): 1308-1313, doi: 10.5858/arpa.2013-0345-RS, indexed in Pubmed: 26414475.

18. Hillestad LK. Acute promyelocytic leukemia. Acta Med Scand. 1957; 159(3): 189-194, indexed in Pubmed: 13508085.

19. Abedin S, Altman JK. Acute promyelocytic leukemia: preventing early complications and late toxicities. Hematology Am Soc Hematol Educ Program. 2016; 2016(1): 10-15, doi: 10.1182/asheducation-2016.1.10, indexed in Pubmed: 27913456.

20. Thomas X. Acute promyelocytic leukemia: a history over 60 years - from the most malignant to the most curable form of acute leukemia. Oncol Ther. 2019; 7(1): 33-65, doi: 10.1007/s40487018-0091-5, indexed in Pubmed: 32700196.

21. Daver N, Kantarjian H, Marcucci G, et al. Clinical characteristics and outcomes in patients with acute promyelocytic leukaemia and hyperleucocytosis. Br J Haematol. 2015; 168(5): 646-653, doi: 10.1111/bjh.13189, indexed in Pubmed: 25312977.

22. Van der Horst C, Stuebinger H, Seif C, et al. Priapism — etiology, pathophysiology and management. Int Braz J Urol. 2003; 29(5): 391-400, doi: 10.1590/s1677-55382003000500002, indexed in Pubmed: 15745583.

23. Stahl M, Tallman MS. Acute promyelocytic leukemia (APL): remaining challenges towards a cure for all. Leuk Lymphoma. 2019; 60(13): 3107-3115, doi: 10.1080/10428194.2019.1613540, indexed in Pubmed: 31842650.

24. Kata D, Kyrcz-Krzemień S. [Acute myelogenous leukemia - recent views on the pathogenesis, diagnostic approach, classification, prognostic stratification and treatment] [Article in Polish]. Post Nauk Med. 2011(7): 601-609.

25. Testa U, Lo-Coco F. Prognostic factors in acute romyelocytic leukemia: strategies to define high-risk atients [Internet]. Vol. 95, Annals of Hematology. Sringer Verlag; 2016 [cited 2021 Jun 2]. Ann Hematol. 2016; 95(5): 673-680, doi: 10.1007/s00277-0162622-1, indexed in Pubmed: 26920716.

26. Walker DK, Held-Warmkessel J. Acute promyelocytic leukemia: an overview with implications for oncology nurses. Clin J Oncol Nurs. 2010; 14(6): 747-759, doi: 10.1188/10.CJON.747-759, indexed in Pubmed: 21112852.

27. Sakata Y, Murakami T, Noro A, et al. The specific activity of plasminogen activator inhibitor-1 in disseminated intravascular coagulation with acute promyelocytic leukemia. Blood. 1991; 77(9): 1949-1957, indexed in Pubmed: 1708294.

28. Wang $Z Y$, Chen $Z$. Acute promyelocytic leukemia: from highly fatal to highly curable. Blood. 2008; 111(5): 2505-2515, doi: 10.1182/ blood-2007-07-102798, indexed in Pubmed: 18299451.

29. Sanz MA, Fenaux P, Tallman MS, et al. Management of acute promyelocytic leukemia: updated recommendations from an expert panel of the European LeukemiaNet. Blood. 2019; 133(15): 1630-1643, doi: 10.1182/blood-2019-01-894980, indexed in Pubmed: 30803991.

30. Choudhry A, DeLoughery T. Bleeding and thrombosis in acute promyelocytic leukemia. Am J Hematol. 2012; 87(6): 596-603, doi: 10.1002/ajh.23158, indexed in Pubmed: 22549696.
31. Naymagon L, Mascarenhas J. Hemorrhage in acute promyelocytic leukemia: can it be predicted and prevented? Leuk Res. 2020; 94: 106356, doi: 10.1016/j.leukres.2020.106356, indexed in Pubmed: 32445941.

32. Jillella AP, Kota VK. The global problem of early deaths in acute promyelocytic leukemia: a strategy to decrease induction mortality in the most curable leukemia. Blood Rev. 2018; 32(2): 89-95, doi: 10.1016/j.blre.2017.09.001, indexed in Pubmed: 29033137.

33. Coombs CC, Tavakkoli M, Tallman MS. Acute promyelocytic leukemia: where did we start, where are we now, and the future. Blood Cancer J. 2015; 5: e304, doi: 10.1038/bcj.2015.25, indexed in Pubmed: 25885425.

34. Di Bona E, Avvisati G, Castaman G, et al. Early haemorrhagic morbidity and mortality during remission induction with or without all-trans retinoic acid in acute promyelocytic leukaemia. Br J Haematol. 2000; 108(4): 689-695, doi: 10.1046/j.13652141.2000.01936.x, indexed in Pubmed: 10792270.

35. Falanga A, Russo L, Tartari CJ. Pathogenesis and treatment of thrombohemorrhagic diathesis in acute promyelocytic leukemia. Mediterr J Hematol Infect Dis. 2011; 3(1): e2011068, doi: 10.4084/ MJHID.2011.068, indexed in Pubmed: 22220265.

36. Sobas M, Czyż A, Montesinos P, et al. Outcome of a real-life population of patients with acute promyelocytic leukemia treated according to the PETHEMA guidelines: the Polish Adult Leukemia Group (PALG) experience. Clin Lymphoma Myeloma Leuk. 2020; 20(2): 105-113, doi: 10.1016/j.clml.2019.09.616, indexed in Pubmed: 31874794.

37. Sanz MA, Montesinos P. Open issues on bleeding and thrombosis in acute promyelocytic leukemia. Thromb Res. 2010; 125: S51-S54, doi: 10.1016/s0049-3848(10)70013-x.

38. Jimenez JJ, Chale RS, Abad AC, et al. Acute promyelocytic leukemia (APL): a review of the literature. Oncotarget. 2020; 11(11): 992-1003, doi: 10.18632/oncotarget.27513, indexed in Pubmed: 32215187.

39. Collins C, Knoderer H. Central nervous system involvement at the time of presentation in acute promyelocytic leukemia. Pediatr Blood Cancer. 2010; 54(4): 603-605, doi: 10.1002/pbc.22348, indexed in Pubmed: 19998465.

40. Sahin DG, Gunduz E, Akay OM, et al. Central nervous system relapse in a patient with acute promyelocytic leukaemia: does the risk stratification matter? BMJ Case Rep. 2013; 2013, doi: 10.1136/bcr-2013-009456, indexed in Pubmed: 23749823.

41. Sultan S, Irfan SM, Ashar S. Acute promyelocytic leukemia: a single center study from Southern Pakistan. Asian Pac J Cancer Prev. 2015; 16(17): 7893-7895, doi: 10.7314/apjcp.2015.16.17.7893, indexed in Pubmed: 26625817.

42. Shameli A, Jamani K. Acute promyelocytic leukemia presenting with atypical basophils. Clin Case Rep. 2020; 8(3): 584-585, doi: 10.1002/ccr3.2686, indexed in Pubmed: 32185069.

43. Das Gupta A, Sapre RS, Shah AS, et al. Cytochemical and immunophenotypic heterogeneity in acute promyelocytic leukemia. Acta Haematol. 1989; 81(1): 5-9, doi: 10.1159/000205390, indexed in Pubmed: 2467498.

44. Mantha S, Tallman MS, Devlin SM, et al. Predictive factors of fatal bleeding in acute promyelocytic leukemia. Thromb Res. 2018; 164 Suppl 1: S98-S9S102, doi: 10.1016/j.thromres.2018.01.038, indexed in Pubmed: 29703492.

45. Lee HJ, Park HJ, Kim HW, et al. Comparison of laboratory characteristics between acute promyelocytic leukemia and other subtypes of acute myeloid leukemia with disseminated intravascular coagulation. Blood Res. 2013; 48(4): 250-253, doi: 10.5045/ br.2013.48.4.250, indexed in Pubmed: 24466548. 
46. $\mathrm{Xu} \mathrm{F}$, Yin $\mathrm{CX}$, Wang CL, et al. Immunophenotypes and immune markers associated with acute promyelocytic leukemia prognosis. Dis Markers. 2014; 2014: 421906, doi: 10.1155/2014/421906, indexed in Pubmed: 25045197.

47. Ren F, Zhang Na, Xu Z, et al. The CD9 CD11b HLA-DR immunophenotype can be used to diagnose acute promyelocytic leukemia. Int J Lab Hematol. 2019; 41(2): 168-175, doi: 10.1111/ ijlh.12929, indexed in Pubmed: 30315692.

48. Tran VT, Phan TT, Mac HP, et al. The diagnostic power of CD117, CD13, CD56, CD64, and MPO in rapid screening acute promyelocytic leukemia. BMC Res Notes. 2020; 13(1): 394, doi: 10.1186/ s13104-020-05235-7, indexed in Pubmed: 32847610.

49. Alcalay M, Zangrilli D, Pandolfi PP, et al. Translocation breakpoint of acute promyelocytic leukemia lies within the retinoic acid receptor alpha locus. Proc Natl Acad Sci U S A. 1991; 88(5): 1977-1981, doi: 10.1073/pnas.88.5.1977, indexed in Pubmed: 1848017.

50. Jensen K, Shiels C, Freemont P. PML protein isoforms and the RBCC/TRIM motif. Oncogene. 2001; 20(49): 7223-7233, doi: 10.1038/sj.onc. 1204765 .

51. Hjalt TA, Murray JC. Genomic structure of the human retinoic acid receptor-alpha1 gene. Mamm Genome. 1999; 10(5): 528-529, doi: 10.1007/s003359901036, indexed in Pubmed: 10337631.

52. Mannan A, Muhsen IN, Barragán E, et al. Role of hematopoietic stem cell transplantation in acute promyelocytic leukemia. Hematol Oncol Stem Cell Ther. 2020; 13(4): 189-201, doi: 10.1016/j. hemonc.2020.05.007, indexed in Pubmed: 32473106.

53. Zelent A, Guidez F, Melnick A, et al. Translocations of the RARalpha gene in acute promyelocytic leukemia. Oncogene. 2001; 20(49): 7186-7203, doi: 10.1038/sj.onc.1204766, indexed in Pubmed: 11704847.

54. Madan V, Shyamsunder P, Han L, et al. Comprehensive mutational analysis of primary and relapse acute promyelocytic leukemia. Leukemia. 2016; 30(8): 1672-1681, doi: 10.1038/leu.2016.69, indexed in Pubmed: 27063598.

55. Lin X, Qiao N, Shen Y, et al. Integration of genomic and transcriptomic markers improves the prognosis prediction of acute promyelocytic leukemia. Clin Cancer Res. 2021; 27(13): 3683-3694, doi: 10.1158/1078-0432.CCR-20-4375, indexed in Pubmed: 33893160 .

56. Zhu HH, Yang MC, Wang F, et al. Identification of a novel NUP98-RARA fusion transcript as the 14th variant of acute promyelocytic leukemia. Am J Hematol. 2020; 95(7): E184-E186, doi: 10.1002/ ajh.25807, indexed in Pubmed: 32242976.

57. Nakanishi T, Nakaya A, Nishio Y, et al. A variant of acute promyelocytic leukemia with $\mathrm{t}(4 ; 17)(\mathrm{q} 12 ; \mathrm{q} 21)$ showed two different clinical symptoms. Hematol Rep. 2019; 11(3): 7971, doi: 10.4081/ hr.2019.7971, indexed in Pubmed: 31579135.

58. Sanz MA, Grimwade D, Tallman MS, et al. Management of acute romyelocytic leukemia: recommendations from an exert anel on behalf of the Euroean LeukemiaNet. Blood. 2009; 113(9): 1875-1891, doi: 10.1182/blood-2008-04-150250, indexed in Pubmed: 18812465.

59. Sanz MA, Lo-Coco F. Modern approaches to treating acute promyelocytic leukemia. J Clin Oncol. 2011; 29(5): 495-503, doi: 10.1200/JCO.2010.32.1067, indexed in Pubmed: 21220600.

60. Lo-Coco F, Avvisati G, Vignetti M, et al. Gruppo Italiano Malattie Ematologiche dell'Adulto, German-Austrian Acute Myeloid Leukemia Study Group, Study Alliance Leukemia. Retinoic acid and arsenic trioxide for acute promyelocytic leukemia. N Engl J Med. 2013; 369(2): 111-121, doi: 10.1056/NEJMoa1300874, indexed in Pubmed: 23841729 .
61. Tallman MS, Andersen JW, Schiffer CA, et al. All-trans retinoic acid in acute promyelocytic leukemia: long-term outcome and prognostic factor analysis from the North American Intergroup protocol. Blood. 2002; 100(13): 4298-4302, doi: 10.1182/ blood-2002-02-0632, indexed in Pubmed: 12393590.

62. Fenaux P, Chastang C, Chevret S, et al. A randomized comparison of all transretinoic acid (ATRA) followed by chemotherapy and ATRA plus chemotherapy and the role of maintenance therapy in newly diagnosed acute promyelocytic leukemia. Blood. 1999; 94(4): 1192-1200, doi: 10.1182/blood. v94.4.1192.416k07_1192_1200.

63. Borlenghi E, Cattaneo $\bar{C}$, Schieppati F, et al. Acute promyelocytic leukemia in patients aged $>70$ years is not rare and highly curable: a single center series of 21 unselected patients. Leuk Lymphoma. 2019; 60(2): 531-534, doi: 10.1080/10428194.2018.1 492126, indexed in Pubmed: 30160625.

64. Sanz MA, Montesinos P, Vellenga E, et al. Risk-adapted treatment of acute promyelocytic leukemia with all-trans retinoic acid and anthracycline monochemotherapy: long-term outcome of the LPA 99 multicenter study by the PETHEMA Group. Blood. 2008; 112(8): 3130-3134, doi: 10.1182/blood-2008-05-159632, indexed in Pubmed: 18664623.

65. Lo-Coco F, Avvisati G, Vignetti M, et al. Italian GIMEMA Cooperative Group. Front-line treatment of acute promyelocytic leukemia with AIDA induction followed by risk-adapted consolidation for adults younger than 61 years: results of the AIDA-2000 trial of the GIMEMA Group. Blood. 2010; 116(17): 3171-3179, doi: 10.1182/ blood-2010-03-276196, indexed in Pubmed: 20644121.

66. Burnett AK, Russell NH, Hills RK, et al. UK National Cancer Research Institute Acute Myeloid Leukaemia Working Group. Arsenic trioxide and all-trans retinoic acid treatment for acute promyelocytic leukaemia in all risk groups (AML17): results of a randomised, controlled, phase 3 trial. Lancet Oncol. 2015; 16(13): 1295-1305, doi: 10.1016/S1470-2045(15)00193-X, indexed in Pubmed: 26384238.

67. Fouzia NA, Sharma V, Ganesan S, et al. Management of relapse in acute promyelocytic leukaemia treated with up-front arsenic trioxide-based regimens. Br J Haematol. 2021; 192(2): 292-299, doi: 10.1111/bjh.17221, indexed in Pubmed: 33216980.

68. Abaza Y, Kantarjian H, Garcia-Manero G, et al. Long-term outcome of acute promyelocytic leukemia treated with all — retinoic acid, arsenic trioxide, and gemtuzumab. Blood. 2017; 129(10): 1275-1283, doi: 10.1182/blood-2016-09-736686, indexed in Pubmed: 28003274.

69. Li X, Wang C, Chen G, et al. Combined chemotherapy for acute promyelocytic leukemia: a meta-analysis. Hematology. 2017; 22(8): 450-459, doi: 10.1080/10245332.2017.1318239, indexed in Pubmed: 28480800.

70. Sasijareonrat N, Jahn N, Ungprasert P, et al. Efficacy and the adverse effects of oral versus intravenous arsenic for acute promyelocytic leukemia: a meta-analysis of randomized-controlled studies. Technol Cancer Res Treat. 2020; 19: 1533033820937008, doi: 10.1177/1533033820937008, indexed in Pubmed: 32583728.

71. Wu F, Wu Di, Ren Y, et al. Bayesian network meta-analysis comparing five contemporary treatment strategies for newly diagnosed acute promyelocytic leukaemia. Oncotarget. 2016; 7(30): 47319-47331, doi: 10.18632/oncotarget.10118, indexed in Pubmed: 27322078 .

72. Sanz J, Labopin M, Sanz MA, et al. Acute Leukemia Working Party of the European Society for Blood and Marrow Transplantation (EBMT). Hematopoietic stem cell transplantation for adults 
with relapsed acute promyelocytic leukemia in second complete remission. Bone Marrow Transplant. 2021; 56(6): 1272-1280, doi: 10.1038/s41409-020-01162-0, indexed in Pubmed: 33323947.

73. Liu Y, Xu J, Chu L, et al. A rare case of acute promyelocytic leukemia with ider(17)(q10)t(15;17)(q22;q21) and favorable outcome. Mol Cytogenet. 2020; 13: 13, doi: 10.1186/s13039-020-00479-1, indexed in Pubmed: 32308740.

74. Schuurhuis GJ, Heuser M, Freeman S, et al. Minimal/measurable residual disease in AML: a consensus document from the European LeukemiaNet MRD Working Party. Blood. 2018; 131(12): 1275-1291, doi: 10.1182/blood-2017-09-801498, indexed in Pubmed: 29330221.

75. Campana D, Coustan-Smith E. Detection of minimal residual disease in acute leukemia by flow cytometry. Cytometry. 1999; 38(4): 139-152, doi: 10.1002/(sici)1097-0320(19990815)38:4<139::aidcyto1>3.0.co;2-h.

76. Kopeć-Szlęzak J, Woźniak J. Standardowe oznaczanie immunofenotypu komórek białaczkowych w rozpoznawaniu i monitorowaniu ostrej białaczki szpikowej (OBS). Now Lek. 2008; 77(4): 273-279.

77. Al-Mawali A, Gillis D, Lewis I. The role of multiparameter flow cytometry for detection of minimal residual disease in acute myeloid leukemia. Am J Clin Pathol. 2009; 131(1): 16-26, doi: 10.1309/ AJCP5TSD3DZXFLCX, indexed in Pubmed: 19095561.

78. Lukes J, Winkowska L, Zwyrtkova M, et al. Identification of fusion gene breakpoints is feasible and facilitates accurate sensitive minimal residual disease monitoring on genomic level in patients with PML-RARA, CBFB-MYH11, and RUNX1-RUNX1T1. Hemasphere. 2020; 4(6): e489, doi: 10.1097/HS9.0000000000000489, indexed in Pubmed: 33204999.

79. Lo-Coco F, Diverio D, Falini B. Genetic diagnosis and molecular monitoring in the management of acute promyelocytic leukemia. Blood. 1999; 94(1): 12-22, indexed in Pubmed: 10381493.

80. Gabert J, Beillard E, van der Velden VHJ, et al. Standardization and quality control studies of 'real-time' quantitative reverse transcriptase polymerase chain reaction of fusion gene transcripts for residual disease detection in leukemia - a Europe Against Cancer program. Leukemia. 2003; 17(12): 2318-2357, doi: 10.1038/ sj.leu.2403135, indexed in Pubmed: 14562125.

81. Zhang Li, Cao Z, Zou Y, et al. Quantification of PML/RARa transcript after induction predicts outcome in children with acute promyelocytic leukemia. Int J Hematol. 2012; 95(5): 500-508, doi: 10.1007/s12185-012-1034-9, indexed in Pubmed: 22407853.

82. Grimwade D, Jovanovic JV, Hills RK, et al. Prospective minimal residual disease monitoring to predict relapse of acute promyelocytic leukemia and to direct pre-emptive arsenic trioxide therapy. J Clin Oncol. 2009; 27(22): 3650-3658, doi: 10.1200/ JCO.2008.20.1533, indexed in Pubmed: 19506161.

83. Brunetti C, Anelli L, Zagaria A, et al. Droplet digital PCR is a reliable tool for monitoring minimal residual disease in acute promyelocytic leukemia. J Mol Diagn. 2017; 19(3): 437-444, doi: 10.1016/j.jmoldx.2017.01.004, indexed in Pubmed: 28268092.

84. Reiter A, Lengfelder E, Grimwade D. Pathogenesis, diagnosis and monitoring of residual disease in acute promyelocytic leukaemia. Acta Haematol. 2004; 112(1-2): 55-67, doi: 10.1159/000077560, indexed in Pubmed: 15179005.

85. Santolaria A, Perales A, Montesinos P, et al. Acute promyelocytic leukemia during pregnancy: a systematic review of the literature. Cancers (Basel). 2020; 12(4), doi: 10.3390/cancers12040968, indexed in Pubmed: 32295152.

86. Mokany E, Todd AV, Fuery CJ, et al. Diagnosis and monitoring of PML-RARalpha-positive acute promyelocytic leukemia by quantitative RT-PCR. Methods Mol Med. 2006; 125: 127-147, doi: 10.1385/1-59745-017-0:127, indexed in Pubmed: 16502582.

87. National Comprehensive Cancer Network - Home. https://www. nccn.org/ (June 3, 2021).

88. Yohe S, Thyagarajan B. Review of clinical next-generation sequencing. Arch Pathol Lab Med. 2017; 141(11): 1544-1557, doi: 10.5858/arpa.2016-0501-RA, indexed in Pubmed: 28782984. 